\title{
Thirty-day medical and surgical readmission following prenatal versus postnatal myelomeningocele repair
}

\author{
Michael Cools, MD, ${ }^{1}$ Weston Northam, MD, ${ }^{1}$ William Goodnight, MD, MSCR, ${ }^{2}$ \\ Graham Mulvaney, MD, ${ }^{3}$ Scott Elton, MD,' and Carolyn Quinsey, MD'
}

${ }^{1}$ Department of Neurosurgery, University of North Carolina School of Medicine; ${ }^{2}$ Maternal Fetal Care Program, Department of Obstetrics and Gynecology, University of North Carolina School of Medicine, Chapel Hill; and ${ }^{3}$ Carolina Neurosurgery and Spine Associates, Carolinas Medical Center, Charlotte, North Carolina

OBJECTIVE Hospital readmission is an important quality metric that has not been evaluated in prenatal versus postnatal myelomeningocele $(\mathrm{MMC})$ repair. This study compares hospital readmission outcomes between these two groups as well as their etiologies.

METHODS The medical records of patients who had undergone MMC repair in the period from 2011 to 2017 at a single academic medical center were retrospectively reviewed. Collected clinical data included surgery and defect details, neonatal intensive care unit (NICU) stay, and any readmissions or surgical procedures up to 1 year after surgery. Patient and defect characteristics, readmission outcomes at 30 and 60 days and 1 year after discharge from the NICU, and cerebrospinal fluid (CSF) diversion surgery rates were analyzed with the two-tailed t-test and/or k-sample test on the equality of medians.

RESULTS A total of 24 prenatal and 34 postnatal MMC repairs were completed during the study period. Prenatally repaired patients were born more prematurely $(p<0.001)$ and with lower birth weights $(p<0.001)$, although the NICU stay was similar between the two groups $(p=0.59)$. Fewer prenatally repaired patients were readmitted at 30 days $(p=$ $0.005), 90$ days $(p=0.004)$, and 1 year $(p=0.007)$ than the postnatal repair group. Hydrocephalus was the most common readmission etiology, and $29 \%$ of prenatal repair patients required CSF diversion at 1 year versus $81 \%$ of the postnatal repair group $(p<0.01)$. Prenatal patients who required CSF diversion had a higher body weight $(p=0.02)$ and an older age $(p=0.01)$ at the time of CSF diversion surgery than the postnatal group.

CONCLUSIONS Patients with prenatal MMC repair had fewer hospital readmissions at 30 days, 60 days, and 1 year than the postnatal repair group, despite similar NICU lengths of stay. The prenatal repair group had lower requirements for CSF diversion at 1 year and was older with greater body weights at the time of CSF diversion surgery, compared to those of the postnatal repair group. Future study of hospital quality metrics such as readmissions should be performed to better understand outcomes of these two procedures.

https://thejns.org/doi/abs/10.3171/2019.7.FOCUS19355

KEYWORDS myelomeningocele; prenatal; postnatal; readmission; hydrocephalus

$\mathrm{M}$ YELOMENINGOCELE (MMC) is a complex congenital neural tube defect involving dorsal herniation of the spinal cord, with resultant leakage of cerebrospinal fluid (CSF) and external exposure of neural elements. ${ }^{1,6}$ Myelomeningocele patients have variable degrees of orthopedic, bowel, and bladder dysfunction; hydrocephalus; and brainstem compression. Their care is complex and multidisciplinary. ${ }^{18}$ Early in life, patients require frequent visits, admissions, and interventions. While their visits often become less frequent, MMC patients need life- long medical care. The life expectancy of these patients has improved over the last few decades, which reflects a need for comprehensive care beyond the initial defect repair surgery. ${ }^{8,27}$

The two options for surgical repair of MMC are well known. Prenatal (intrauterine) repair has been compared to postnatal repair in terms of the need for surgical treatment of hydrocephalus and subsequent revision, severity of symptomatic Chiari malformation, ambulation, urological function, and retethering..$^{1,3,5,12,25}$ Prenatal repair

ABBREVIATIONS CSF = cerebrospinal fluid; ETV = endoscopic third ventriculostomy; MMC = myelomeningocele; NICU = neonatal intensive care unit; NSQIP = National Surgical Quality Improvement Program. 
has reduced requisite surgical treatment of hydrocephalus, with improvement in motor and neurodevelopmental outcomes. ${ }^{11}$ However, prenatal repair introduces additional risk to the fetus and the expectant mother, including preterm birth. ${ }^{14}$ Preterm birth, differences in urological function, secondary effects of reducing hydrocephalus treatment, as well as other factors, have implications immediately postdischarge and throughout a patient's life, which have not been characterized.

Readmission has become an important quality metric for all surgical populations, including the pediatric neurosurgery population. ${ }^{7,16,23,28}$ A recent study of the pediatric neurosurgical population found that postnatal MMC repair had a readmission rate of $14 \%$ within 30 days, which accounted for $15 \%$ of all unplanned readmissions. ${ }^{23} \mathrm{~A} \mathrm{Na}-$ tional Surgical Quality Improvement Program (NSQIP) study of postnatal MMC patients found frequent readmissions for hydrocephalus-related causes as well as for wound dehiscence. ${ }^{6}$ However, hospital readmission outcomes within the prenatal MMC population remain unclear. This study compares readmission and etiology of readmission in patients who underwent prenatal versus postnatal repair of MMC to better understand immediate postsurgical hospital care in these populations.

\section{Methods}

This study was approved by the University of North Carolina institutional review board. We conducted a retrospective review of the medical records of MMC patients who had undergone prenatal or postnatal MMC repair between 2011 and 2017 at a single academic medical center. We queried the medical records for details about operative MMC repair, neonatal intensive care unit (NICU) stay, and any readmissions or surgical procedures the patient had at 30 days, 60 days, and 1 year following discharge from the NICU. We also queried the records regarding the need for CSF diversion and subsequent treatment.

Patients were excluded if they had not been born at our institution or had received postoperative care elsewhere resulting in fragmented or missing follow-up in our medical record system. All data were analyzed using Stata software (StataCorp LLC). Means were compared using a two-tailed t-test. Medians were compared using a k-sample test on the equality of medians.

\section{Results}

A total of $58 \mathrm{MMC}$ repairs were performed at our institution in the study period, and 24 were prenatal and 34 were postnatal (Table 1). The average gestational age at repair was 24.4 weeks for the prenatally repaired patients. All postnatal repairs were completed within 48 hours of birth. Patients undergoing prenatal repair were on average born significantly more prematurely (32.1 vs 36.9 weeks, $p$ $<0.001)$ and had a significantly lower birth weight (1.8 vs $2.8 \mathrm{~kg}, \mathrm{p}<0.001)$ than the postnatal group. There was no significant difference in the percentage of patients with a lesion at L3 or below between the groups (66.7\% prenatal vs $67.6 \%$ postnatal, $p=0.97$ ). The NICU length of stay was not significantly different between the two cohorts (median stay 25.5 days prenatal vs 17 days postnatal, $\mathrm{p}=0.59$ ).
TABLE 1. Patient and defect characteristics in postnatal and prenatal groups

\begin{tabular}{lllc}
\hline \multicolumn{1}{c}{ Variable } & \multicolumn{1}{c}{ Prenatal } & Postnatal & p Value \\
\hline No. of pts & 24 & 34 & \\
\hline Females & $12(50 \%)$ & $19(55.9 \%)$ & 0.66 \\
\hline Birth weight in kg (SD) & $1.8(0.61)$ & $2.8(0.88)$ & $<0.001$ \\
\hline GA at birth in wks (SD) & $32.1(3.1)$ & $36.9(3.4)$ & $<0.001$ \\
\hline $\begin{array}{l}\text { Median LOS in NICU in } \\
\text { days (range) }\end{array}$ & $25.5(5.5-41.5)$ & $17(10-48)$ & 0.59 \\
\hline $\begin{array}{l}\text { Mean LOS in NICU in } \\
\text { days (SD) }\end{array}$ & $34.1(33.0)$ & $30.9(35)$ & 0.73 \\
\hline GA at repair in wks (SD) & $24.4(0.3)$ & & \\
\hline Age at repair in days & NA & $1(0-2)$ & \\
(range) & & & \\
\hline Level of defect & & & \\
\hline Thoracic & $0(0 \%)$ & $4(11.8 \%)$ & \\
\hline L1 & $1(4.2 \%)$ & $4(11.8 \%)$ & \\
\hline L2 & $5(20.8 \%)$ & $1(2.9 \%)$ & \\
\hline L3 & $6(25.0 \%)$ & $9(26.5 \%)$ & \\
\hline L4 & $6(25.0 \%)$ & $7(20.6 \%)$ & \\
\hline L5 & $4(16.7 \%)$ & $5(14.7 \%)$ & \\
\hline Sacral & $0(0 \%)$ & $2(5.9 \%)$ & \\
\hline Not documented & $2(8.3 \%)$ & $2(5.9 \%)$ & \\
\hline Lesion at L3 or lower & $16(66.7 \%)$ & $23(67.6 \%)$ & 0.97 \\
\hline
\end{tabular}

$\mathrm{GA}=$ gestational age; $\mathrm{LOS}=$ length of stay; $\mathrm{NA}=$ not applicable; pts = patients .

* Two patients in each group did not have data on the level of defect.

At 30 days, 1 patient in the prenatal group (5\%) had been readmitted, compared with $13(39 \%)$ in the postnatal group ( $p=0.005$; Table 2 ). This difference between the two groups persisted at 90 days $(19 \%$ vs $57 \%, \mathrm{p}=0.004)$ and at 1 year $(47 \%$ vs $85 \%, \mathrm{p}=0.007)$. The most common reason for readmission among all patients at 30 days was hydrocephalus, followed by wound dehiscence; other causes included urinary tract infection, fever, and respiratory illnesses. One patient in the postnatal group was readmitted 11 days after discharge with apneic episodes related to Chiari malformation type II and brainstem compression.

At 1 year, 5 (29\%) of 17 prenatal MMC repair patients with at least 1 year of follow-up required CSF diversion, compared to $22(81 \%)$ of 27 postnatal repair patients (p $<0.01$; Table 3). The majority of patients requiring CSF diversion underwent placement of a ventriculoperitoneal shunt (24/27 [89\%]), while a minority underwent endoscopic third ventriculostomy (ETV; 3/27 [11\%]). Among those patients requiring CSF diversion, the prenatal MMC patients were heavier $(7.0 \mathrm{vs} 4.5 \mathrm{~kg}, \mathrm{p}=0.02)$ and older $(7.2$ vs 2.2 months, $\mathrm{p}=0.01)$. Shunt survival rates were similar between the two groups. Of those patients undergoing shunt placement with 6 months of follow-up, 2 (40\%) of 5 patients in the prenatal group and $10(45 \%)$ of 22 patients in the postnatal group required revision. For those patients with at least 1 year of follow-up after shunt placement, 3 $(60 \%)$ of 5 in the prenatal group required revision compared with $12(57.1 \%)$ of 21 in the postnatal group. Of the 3 
TABLE 2. Reasons for hospital readmission at $\mathbf{3 0}$ days, 90 days, and 1 year

\begin{tabular}{|c|c|c|c|}
\hline Variable & Prenatal & Postnatal & $p$ Value \\
\hline 30-day readmission & $1(5 \%)$ & $13(39 \%)$ & 0.005 \\
\hline No. of pts w/ data & 21 & 33 & \\
\hline Hydrocephalus related & 0 & $6(46 \%)$ & \\
\hline Wound dehiscence & 0 & $3(23 \%)$ & \\
\hline UTI & 0 & $1(8 \%)$ & \\
\hline Fever & $1(100 \%)$ & 0 & \\
\hline Respiratory illness & 0 & $1(8 \%)$ & \\
\hline Other & 0 & $2(15 \%)$ & \\
\hline 90-day readmission & $4(19 \%)$ & $17(57 \%)$ & 0.004 \\
\hline No. of pts w/ data & 21 & 30 & \\
\hline Hydrocephalus related & $2(50 \%)$ & $8(47 \%)$ & \\
\hline Wound dehiscence & 0 & $3(18 \%)$ & \\
\hline UTI & 0 & $1(6 \%)$ & \\
\hline Fever & $2(50 \%)$ & $1(6 \%)$ & \\
\hline Respiratory illness & 0 & $2(12 \%)$ & \\
\hline Other & 0 & $2(12 \%)$ & \\
\hline 1-yr readmission & $8(47 \%)$ & $23(85 \%)$ & 0.007 \\
\hline No. of pts w/ data & 17 & 27 & \\
\hline Hydrocephalus related & $2(25 \%)$ & $11(48 \%)$ & \\
\hline Wound dehiscence & 0 & $4(17 \%)$ & \\
\hline UTI & $1(12.5 \%)$ & $3(13 \%)$ & \\
\hline Fever & $2(25 \%)$ & $1(4 \%)$ & \\
\hline Respiratory illness & $2(25 \%)$ & $2(9 \%)$ & \\
\hline Other & $1(12.5 \%)$ & $2(9 \%)$ & \\
\hline
\end{tabular}

$\mathrm{UTI}=$ urinary tract infection.

patients who underwent ETV (1 in prenatal group and 2 in postnatal group), none has needed revision or placement of a shunt with at least 7 months of follow-up.

\section{Discussion}

This study compares the 30-day, 90-day, and 1-year readmission rates between prenatal and postnatal MMC repair groups. We found that patients who had undergone prenatal MMC repair had significantly lower readmission rates at all endpoints following discharge from the NICU. The most common reason for readmission was hydrocephalus in both groups, followed by wound complications in the postnatal group. The prenatal repair group also needed CSF diversion at a lower rate than the postnatal repair patients, consistent with prior research..$^{1,25}$

Readmissions are used as a quality metric in evaluations of both surgeons and hospitals, ${ }^{16}$ and understanding such metrics is an important step in improving quality. Several studies of the pediatric neurosurgical population have evaluated causes of readmissions. A single-center study of readmissions found a rate of $11 \%$ within 30 days and $18 \%$ within 90 days. ${ }^{7}$ To date, no study has reported readmission rates for prenatal MMC repair patients. However, some studies have reported rates of readmission within the postnatal MMC repair population. A review of the NSQIP
TABLE 3. Differences in the CSF diversion requirement, with age and weight at the time of surgery

\begin{tabular}{lccc}
\hline \multicolumn{1}{c}{ Variable } & Prenatal & Postnatal & p Value \\
\hline $\begin{array}{l}\text { Requiring CSF diversion at } \\
1 \mathrm{yr}\end{array}$ & $5 / 17(29 \%)$ & $22 / 27(81 \%)$ & $<0.01$ \\
$\begin{array}{l}\text { Weight at CSF diversion in } \\
\mathrm{kg}(\mathrm{SD})\end{array}$ & $7.0(3.6)$ & $4.5(2.6)$ & 0.02 \\
$\begin{array}{c}\text { Age at CSF diversion in mos } \\
\text { (SD) }\end{array}$ & $7.2(5.9)$ & $2.2(4.0)$ & 0.01 \\
$\begin{array}{c}\text { Shunt survival at 6 mos after } \\
\text { placement }\end{array}$ & $3 / 5(60 \%)$ & $12 / 22(55 \%)$ & \\
$\begin{array}{c}\text { Shunt survival at 1 yr after } \\
\text { placement }\end{array}$ & $2 / 5(40 \%)$ & $9 / 21(43 \%)$ & \\
\hline
\end{tabular}

database demonstrated an overall unplanned readmission rate of $11 \%$ at 30 days. ${ }^{6}$ While our readmission rate for postnatal MMC is higher than the rate in that study (39\% vs $11 \%$ ), we included admissions for hydrocephalus including elective shunt placement, likely contributing to a higher readmission rate. However, we considered these readmissions important to include, as they gave a more complete picture of the patient's overall health and time in the hospital.

Prematurity has been associated with an increased risk of readmission, both in the general pediatric population ${ }^{28}$ and in the pediatric neurosurgical population. ${ }^{7}$ These premature patients often have medical comorbidities resulting in prolonged NICU stays and increased readmission rates. Additionally, parents and providers may be more vigilant in these populations, with a lower threshold for readmission. As previously established, our data indicated that prenatal MMC patients are more likely to be born prematurely. In a study of postnatally repaired MMC, prematurity was not associated with increased readmission rates. ${ }^{6}$ In our study, the decreased rate of readmissions in prenatally repaired patients is likely attributable to the lower rates of requisite CSF diversion. Complications of shunts and failed ETVs are common reasons for readmission in the pediatric neurosurgical population in general ${ }^{7,19,23,24}$ and the MMC population specifically. ${ }^{4,6,10,15,26}$

Hydrocephalus contributed the most to the difference in readmission rates between prenatal and postnatal repair. Within the 1st year, only 2 patients who had undergone prenatal repair were readmitted for hydrocephalusrelated issues, compared to 11 of the postnatally repaired patients. While the different rates of CSF diversion explain much of this difference, there were also differences in the timing of hydrocephalus treatment. We found that patients undergoing prenatal MMC repair weighed more and were older at the time of CSF diversion. MMC patients have a relatively elevated rate of revisions per patient in the 1st year of life, with a subsequent decline in shunt malfunction over a lifespan. ${ }^{4,10}$ Several studies have shown benefit from CSF diversions at older ages. ${ }^{2,9,17,20,21}$ Shunts placed into infants younger than 6 months of age increase the risk for shunt malfunction ${ }^{22}$ and infection. ${ }^{20}$ Additionally, a low body weight is a risk factor for negative shunt outcomes. ${ }^{13,17}$ Thus, MMC patients undergoing prenatal 
repair may benefit not only from a lower risk of requisite shunting, but also from a heavier weight and an older age if CSF diversion is required.

This study is limited by its single-center nature, resulting in a relatively low number of patients. With a small cohort, identifying predictive factors for readmission within each group was not feasible. Larger studies incorporating all centers performing prenatal MMC repair would be informative for counseling expectant parents about the risks and benefits of prenatal versus postnatal MMC repair. We were also only able to capture readmissions to our institution. It is possible that some patients were readmitted to other hospitals without our knowledge. However, given the medical complexity of these patients, we believe most would have been transferred to our institution if there had been a need for admission and ongoing care. Another limitation is the lack of the standardization of treatments for hydrocephalus. An individual surgeon clinically decides to treat hydrocephalus, as well as whether to place a shunt or perform ETV.

\section{Conclusions}

While patients undergoing prenatal MMC repair were born more prematurely than those undergoing postnatal MMC repair, they still had significantly lower readmission rates at 30 days, 90 days, and 1 year, despite similar NICU lengths of stay. Additionally, prenatally repaired patients required fewer CSF diversion procedures at 1 year, and when they did require CSF diversion, they were significantly heavier and older, which could contribute to greater long-term shunt survival. This study provides the first comparison of hospital readmission rates between prenatal and postnatal MMC repair patients and indicates that further study of hospital quality metrics such as readmission is important to understand the differential outcomes of these procedures.

\section{Acknowledgments}

We would like to thank Dr. Kathryn Pietrosimone for her work in editing and revising the manuscript.

\section{References}

1. Adzick NS, Thom EA, Spong CY, Brock JW III, Burrows PK, Johnson MP, et al: A randomized trial of prenatal versus postnatal repair of myelomeningocele. N Engl J Med 364:993-1004, 2011

2. Berry JG, Hall MA, Sharma V, Goumnerova L, Slonim AD, Shah SS: A multi-institutional, 5-year analysis of initial and multiple ventricular shunt revisions in children. Neurosurgery 62:445-454, 2008

3. Brock JW III, Carr MC, Adzick NS, Burrows PK, Thomas JC, Thom EA, et al: Bladder function after fetal surgery for myelomeningocele. Pediatrics 136:e906-e913, 2015

4. Caldarelli M, Di Rocco C, La Marca F: Shunt complications in the first postoperative year in children with meningomyelocele. Childs Nerv Syst 12:748-754, 1996

5. Cavalheiro S, da Costa MDS, Moron AF, Leonard J: Comparison of prenatal and postnatal management of patients with myelomeningocele. Neurosurg Clin N Am 28:439448, 2017

6. Cherian J, Staggers KA, Pan IW, Lopresti M, Jea A, Lam S: Thirty-day outcomes after postnatal myelomeningocele re- pair: a National Surgical Quality Improvement Program Pediatric database analysis. J Neurosurg Pediatr 18:416-422, 2016

7. Chotai S, Guidry BS, Chan EW, Sborov KD, Gannon S, Shannon C, et al: Unplanned readmission within 90 days after pediatric neurosurgery. J Neurosurg Pediatr 20:542_ 548, 2017

8. Davis BE, Daley CM, Shurtleff DB, Duguay S, Seidel K, Loeser JD, et al: Long-term survival of individuals with myelomeningocele. Pediatr Neurosurg 41:186-191, 2005

9. Di Rocco C, Marchese E, Velardi F: A survey of the first complication of newly implanted CSF shunt devices for the treatment of nontumoral hydrocephalus. Cooperative survey of the 1991-1992 Education Committee of the ISPN. Childs Nerv Syst 10:321-327, 1994

10. Dupepe EB, Hopson B, Johnston JM, Rozzelle CJ, Jerry Oakes W, Blount JP, et al: Rate of shunt revision as a function of age in patients with shunted hydrocephalus due to myelomeningocele. Neurosurg Focus 41(5):E6, 2016

11. Farmer DL, Thom EA, Brock JW III, Burrows PK, Johnson MP, Howell LJ, et al: The Management of Myelomeningocele Study: full cohort 30-month pediatric outcomes. Am J Obstet Gynecol 218:256.e1-256.e13, 2018

12. Horst M, Mazzone L, Schraner T, Bodmer C, Möhrlen U, Meuli M, et al: Prenatal myelomeningocele repair: do bladders better? Neurourol Urodyn 36:1651-1658, 2017

13. James HE, Bejar R, Gluck L, Coen R, Merritt A, Mannino $\mathrm{F}$, et al: Ventriculoperitoneal shunts in high risk newborns weighing under 2000 grams: a clinical report. Neurosurgery 15:198-202, 1984

14. Johnson MP, Bennett KA, Rand L, Burrows PK, Thom EA, Howell LJ, et al: The Management of Myelomeningocele Study: obstetrical outcomes and risk factors for obstetrical complications following prenatal surgery. Am J Obstet Gynecol 215:778.e1-778.e9, 2016

15. Kellogg R, Lee P, Deibert CP, Tempel Z, Zwagerman NT, Bonfield CM, et al: Twenty years' experience with myelomeningocele management at a single institution: lessons learned. J Neurosurg Pediatr 22:439-443, 2018

16. Khan A, Nakamura MM, Zaslavsky AM, Jang J, Berry JG, Feng JY, et al: Same-hospital readmission rates as a measure of pediatric quality of care. JAMA Pediatr 169:905-912, 2015

17. Liptak GS, McDonald JV: Ventriculoperitoneal shunts in children: factors affecting shunt survival. Pediatr Neurosci 12:289-293, 1985-1986

18. Mukherjee S, Pasulka J: Care for adults with spina bifida: current state and future directions. Top Spinal Cord Inj Rehabil 23:155-167, 2017

19. Patwardhan RV, Nanda A: Implanted ventricular shunts in the United States: the billion-dollar-a-year cost of hydrocephalus treatment. Neurosurgery 56:139-145, 2005

20. Piatt JH Jr, Carlson CV: A search for determinants of cerebrospinal fluid shunt survival: retrospective analysis of a 14-year institutional experience. Pediatr Neurosurg 19:233-242, 1993

21. Reddy GK, Bollam P, Caldito G: Long-term outcomes of ventriculoperitoneal shunt surgery in patients with hydrocephalus. World Neurosurg 81:404-410, 2014

22. Riva-Cambrin J, Kestle JRW, Holubkov R, Butler J, Kulkarni $\mathrm{AV}$, Drake J, et al: Risk factors for shunt malfunction in pediatric hydrocephalus: a multicenter prospective cohort study. $\mathbf{J}$ Neurosurg Pediatr 17:382-390, 2016

23. Sherrod BA, Johnston JM, Rocque BG: Risk factors for unplanned readmission within 30 days after pediatric neurosurgery: a nationwide analysis of 9799 procedures from the American College of Surgeons National Surgical Quality Improvement Program. J Neurosurg Pediatr 18:350-362, 2016 
24. Simon TD, Riva-Cambrin J, Srivastava R, Bratton SL, Dean JM, Kestle JRW: Hospital care for children with hydrocephalus in the United States: utilization, charges, comorbidities, and deaths. J Neurosurg Pediatr 1:131-137, 2008

25. Tulipan N, Wellons JC III, Thom EA, Gupta N, Sutton LN, Burrows PK, et al: Prenatal surgery for myelomeningocele and the need for cerebrospinal fluid shunt placement. J Neurosurg Pediatr 16:613-620, 2015

26. Wetzel JS, Heaner DP, Gabel BC, Tubbs RS, Chern JJ: Clinical evaluation and surveillance imaging of children with myelomeningocele and shunted hydrocephalus: a follow-up study. J Neurosurg Pediatr 23:153-158, 2018

27. Yen IH, Khoury MJ, Erickson JD, James LM, Waters GD, Berry RJ: The changing epidemiology of neural tube defects. United States, 1968-1989. Am J Dis Child 146:857-861, 1992

28. Young PC, Korgenski K, Buchi KF: Early readmission of newborns in a large health care system. Pediatrics 131:e1538-e1544, 2013

\section{Disclosures}

The authors report no conflict of interest concerning the materials or methods used in this study or the findings specified in this paper.

\section{Author Contributions}

Conception and design: Quinsey, Cools, Goodnight, Elton. Acquisition of data: Cools, Mulvaney. Analysis and interpretation of data: Mulvaney. Drafting the article: Cools, Northam. Critically revising the article: Quinsey, Cools, Northam, Goodnight, Elton. Reviewed submitted version of manuscript: all authors. Approved the final version of the manuscript on behalf of all authors: Quinsey. Statistical analysis: Mulvaney.

\section{Correspondence}

Carolyn Quinsey: University of North Carolina School of Medicine, Chapel Hill, NC. carolyn_quinsey@med.unc.edu. 